\title{
The incidence of peri-renal abscess in urinary tract infections
}

\author{
H. T. Gozdas · O. Karabay
}

Received: 23 November 2012/ Accepted: 21 December 2012/Published online: 15 January 2013

(C) Springer-Verlag Berlin Heidelberg 2013

Dear Editor,

We have read the recent article by Duchêne et al. [1] with great interest. Peri-renal abscess is an extremely rare complication of urinary tract infections. The incidence of peri-renal abscess is defined in the literature as approximately $1 / 10,000$ [2]. However, the authors reported perirenal abscess in 2 out of 80 patients in their study (2.5\%). Their frequency of peri-renal abscess is very high compared to the literature.

Which diagnostic tool did the authors use for the diagnosis of peri-renal abscess? According to which criteria did they make the diagnosis? To what did the authors attribute this high frequency? As readers, we will be very grateful to hear the comments of the authors about this topic.

Conflict of interest None declared.

\section{References}

1. Duchêne E, Montassier E, Boutoille D, Caillon J, Potel G, Batard E. Why is antimicrobial de-escalation under-prescribed for urinary tract infections? Infection. 2012 (in press).

2. Gardiner RA, Gwynne RA, Roberts SA. Perinephric abscess. BJU Int. 2011;107:20-3. 